BRTTISH MEDICAL JOURNAL VOLUME $285 \quad 2$ OCTOBER 1982 PRACTICE OBSERVED

\section{Research in General Practice}

\section{Clinical trial in general practice?}

NIGEL $C$ H STOTT

Why I started

Any doctor worth his or her salt should be asking questions
anbout the fascinating array of problems sobout which we are
consulted every day consulted every day. The finest aspect of general practice is
its colourful diversity, and yet even this has been seen as a disadvantage by those who think that only specialist clinics
see enough material of a unified nature to permit rescarch There are many arces of the generalist's work that are highly
suited to rescarch: one of these is scute respiratory tract
infections, which form about $60 \%$ of the work load of docctors

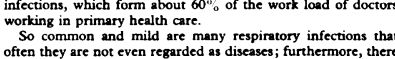

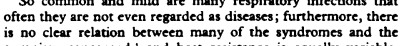
is no clear relation between many of the syndromes and the
organism concerede,', and host resistance es equally variable.
Dietery, socioeconomic, hereditary, family, and atmospheric factors all modify the individual's experience of respiratory
symptoms and diseases. Doctors also show very divere habits
in diagnosing the indivivual syndromes,' and antibiotics are in diagnosing the individual syndromes,' and antibiotics are
often overprescribed, to the detriment of the environment, the patient's expectations, and the person who foots the bill.
Cots Clear guidelines for treatement are difficult to formulate
because of this lack of insight into the environment-host-

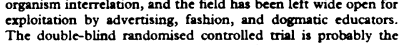
The double-blind randomised controlled trial is probably the
best way to begin to provide some of the answers to such
awkward questions because it is possible to control for many

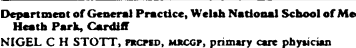

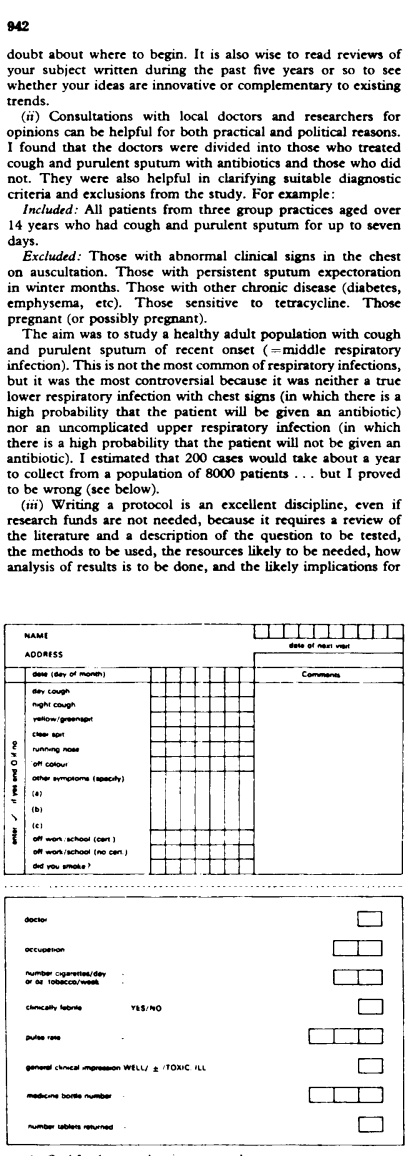

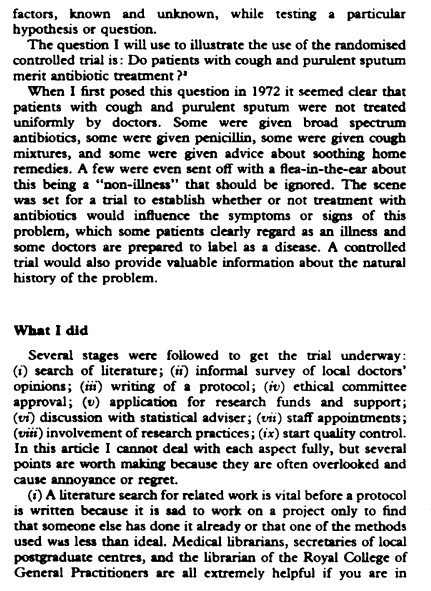

BRTTSH MEDICAI JOURNAI VOLUME $285 \quad 2$ OCTOBER 1982 the future. I had decided to try to answer two basic questions:
(a) Does antibiotic treatment modify the clinical coursc of

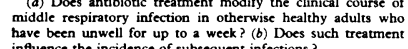

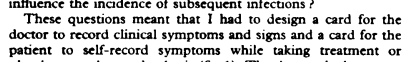
patient to self-record symptoms while taking treatment of
placebo on a day-to-day basis (fig 1). The doctors had to agree
to review the patients at the end of weck 1 and stop treatrenen

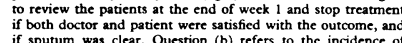
infections brought to the doctor and implies a need for either patient self-recording for a further six months (which is
impractical) or unisg practics that keep good medidal
records to ensure that all day and night consultations and visis

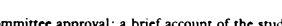

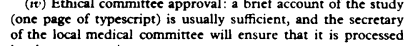
by the next meeting.
$(v)$ A clinical trial often involves drug treatment, and pharma-

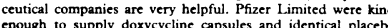
enough to supply doxycycline capsules and identical placebo
capsules in randomised, numbered botrles. The randomisation code was supplied in a sealed envelope and held by the statistical
adviser until the proiect was completed. This meant that $a$
DouBLE-BLIND format was achieved with neither doctor not

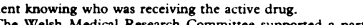
time health visitor to assist with fieldwork and quality control. Every area has local research committces that supply small
grants, but consultation with local academics will always help an asset and $a$ friend, saves no end of time, and will do all the inalysis of data, which few clinicians have the inclination or the
skills to perform. If he does undertake more than advice do
consider including him as a co-author-it is courteous and builds happier relationships for later projects.
(vii) Staff appointments are often necessary in clinical trials because clerical and feldwork can be tedious or impossible if but practice managers are also helpful and many research or
academic institutions will act as an "umbrella" for the general practice researcher and provide help with such matters. See
he departmental head and you can expect a warm reception ii you have done your homework and know what you hope to do.
(viii) Qualisy control of data is a recurrent nightmare for mashed by discovering that observers are inconsistent

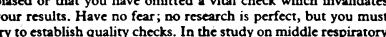
try to establish qualiry checks. In the study on middle respiratory (a) Alltion 22 doctors who particicarted were briefed by the
(ascarcher and subiected to a blind clinical signs study in which a series of patients seen by the doctors in their own
surgeries were also auscultated by an independent clinician. Both doctors recorded the objective signs independently. This
was repeated until the researcher was sacisfied that chest signs

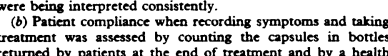
returned by patients at the end of treatment and by a health
visitor calling at the homes of a one-in-ifice sample of patients
during the first week of trearment to check on recording and capsule count. The patients were not told that the health
visitor would be calling
(c) Respiratory diagnoses were checked daily on doctors' is in doubt.
(vi) A statistical adviser who is concerned from the outset is

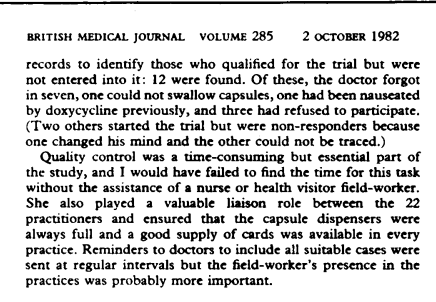

What I found

The first discovery was that I could not complete the study
in one year as my estimates about the frequency of middle respiratory tract infection had boen optimistic. This is a very
common error in clinical trials and hard to avoid because on is never $100^{\circ}$ in sure about the incidence of anything untail
full survey is completed. Opinions are notoriously unreliable and even a pilot study can lead to gross miscalculation.
The most important finding is illustrated in fig 2 . Doxycyclin

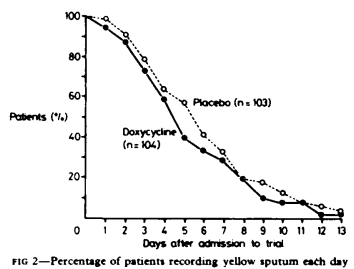

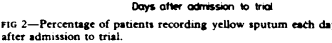

and placebo groups were no different, whether judged by
symptoms or duration of illness, purulent spptum, or inme of
school or work The figure also illustrates the narural history

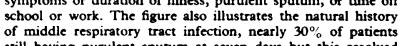
of middle respiratory tract infection, nearly $30 \%$ of patients
still having purulent spurtum at seven days but chis resolved
over the next seven days. Similar trends were seen for other over the next seven days. Similar trends were seen for other
symptoms (cough, malaise, fever, headache, etc).
Could the results be beased ? Y Yes, all results can be biased, Could the results be biased? Yes, all results can be biased
even those from double-blind randomised controlled trials
the randomisarion process fails to provised rwo tidentical the randomisarion process fails to provide two identical groups
for study. This can happen by chance, and it is another night-
mare for the researcher when he or she analyses the results. mare for the researcher when he or she analyses ther results
Fortunately, this study did not suffer from this chance defecec but we had to show that the groups were balanced by age, sex,
symptoms on entry, duration of illness, severity of illhess.
compliance with drug taking, occupation, and smoking habits.

SLDE EFFECTS OF TREATMENT

All treatments have some possible side effects, and a drus
chat causes rashes or nausea or diarrhoea is much less likely of

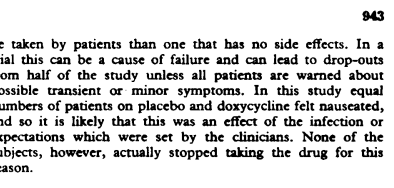
The lessons I learnt

(1) Always allow $\mathbf{5 0 \%}$ additional time on your estimate for proiect duration.
(2) Plan for adequate ficldwork or clinical assistance, or both,
even if you think that your presents staff can carry the additional (3) Take advice from as many sourcess as possible before
starting the project. This helps to avoid mistakes and miscartcing the project. This helps to avoid mistakes and mis-
calcultions, but it is time-consuming
(4) The randomised controlled trial is a very powerful research

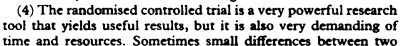
groups cannot be shown until very large numbers of cases are recruited into the trial. A statistician must guide you or you
will be tempted to take short-cuts that you will regret sub-

The conclusions I was able to draw Six years after the project on middle respiratory tract infection
was published I find myself identifying two vets of conclusions to their doctors with cough and purulent spun of up seven days' duration and whose chests show no abnormal
signs on auscultation-that is, middle respiratory tract infection -usually get better as quickly without as with antibiotic treat-
ment. This finding has also been corroborated by controlled trials in chldren with various respiratory infections and in adults given carly treatment for colds and infuenza-inke
iilness.-- This study alaso provided useful information about
the natural history of middle respiratory tract infection by the natural history of middle respiratory tract infection by
confirming that it is susual for sympoms to persist for up too
week, and in a third of patients they persist for several day week, and in a third of patients they persist for several days
longer. Patients can now be told what to expect, and his is is
very important part of mangement, which other work has also highlighted.'
A second set of conclusions relates to the way the results of the study have been used by doctors and researchers since
publication: it has been disappointing to find that many clinicians continue to prescribe antibiotices for middlete respiratory
tract infection, and the strudy has been misquuoted in defence
of this strategr. In has also been misquoted in defenence of not giving antibiotics to patients with chronic bronchitis with acute
exacerbation. I can only conclude that some clinicians seck to exacerbacion. Il can only conclude that some clinicians seck to
justify their clinical behaviour by misuse of referencers. Perthaps
if more clinicians conducted clinical trials themselves they if more clinicians conducted clinical trials themselves they
would tearn how cautiously one has to interpret original work and that one devailed suddy can only provide a further frazgene
for the patchwork quilt of knowledge that we call science.

Opportunities for similar research

Evidence for the limited efficacy of antibiotics in many
respiratory tract infections is now well documented, but there
is a paucity of controlled clinical research into the relative is a paucity of controlicd clinical research into the relative
efficacy of efficacy of substances that are supposed to provide symptomatic
relief. Anal gesics, decongestants, cought suppressensts, ex-
pectorants, and soothing vapours are all used, but do they have
\

बำ

is

$\vec{\circ}$

$\overrightarrow{\vec{\omega}}$

호․

兽

డ్ల

के

$\stackrel{\wp}{\risingdotseq}$

옥

N

응

Ф

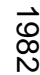

8

용

Two changes in the pateren of British genceral practice over the
past two decades have increased the need for good communica

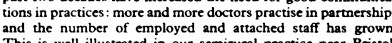

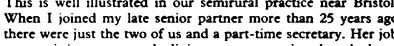

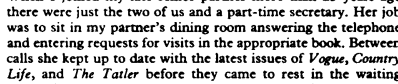

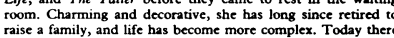

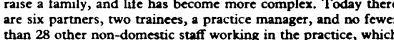

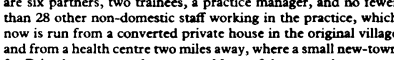

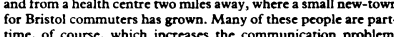

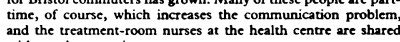

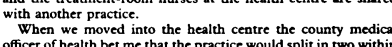

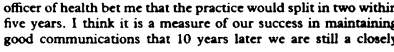

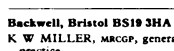

knit practice and fully expect to remain so. No partner has ever

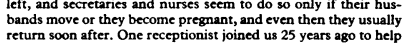

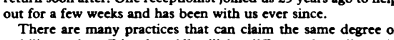

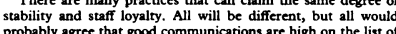

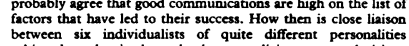

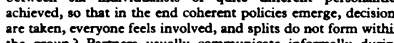
the group? Parneres susuallycom, communicicate informally y during

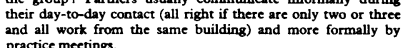
Practice meetings

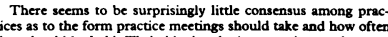

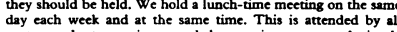
partrers, the two traines, and the practice managerer. A simple

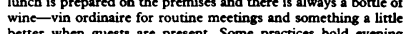
better when guests are present. Some practices bold evening

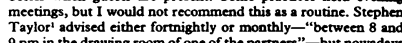

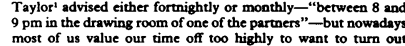




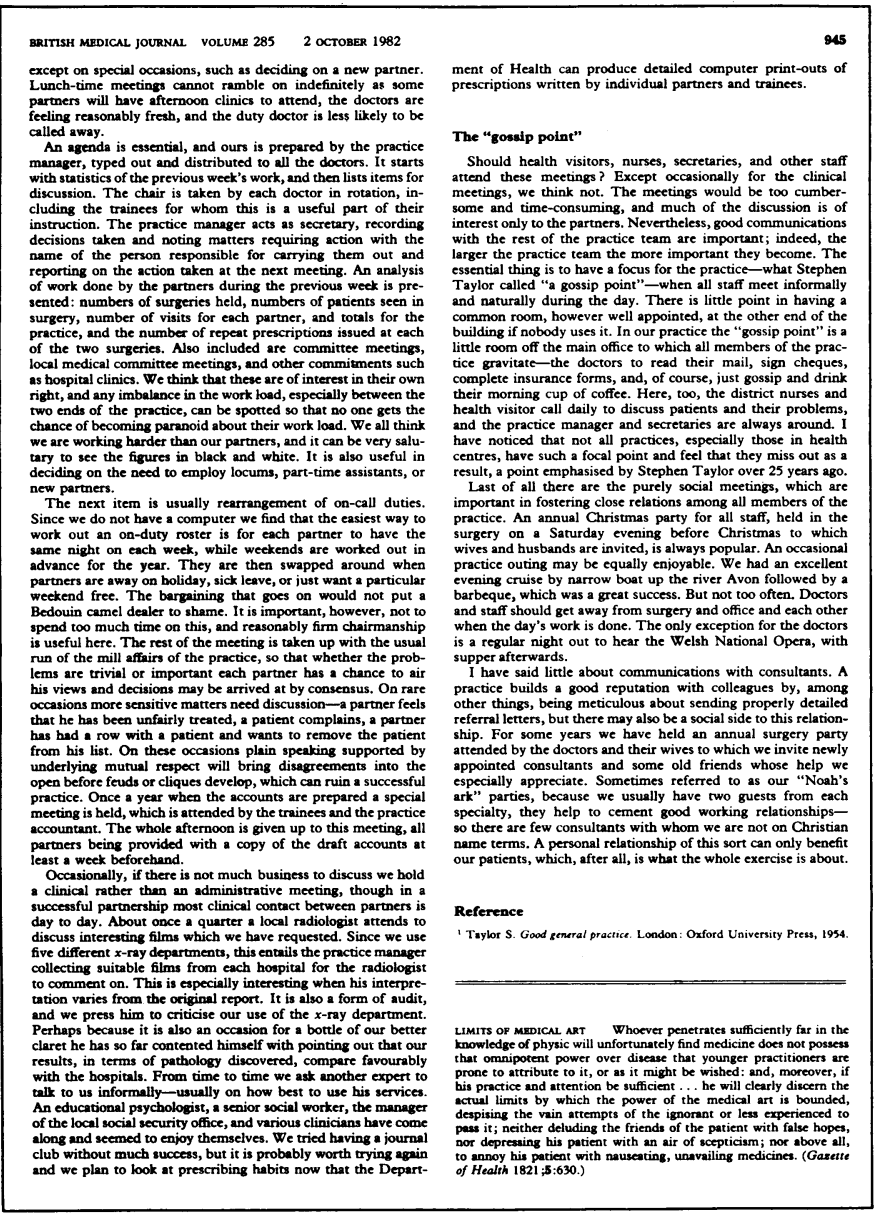

246

BRTISH MEDICAL JOURNAL VOLUME $285 \quad 2$ OCTOBER 1982

\section{Shortlisting Trainees}

\section{Thoughtful applications wanted in Birmingham}

K G DICKINSON

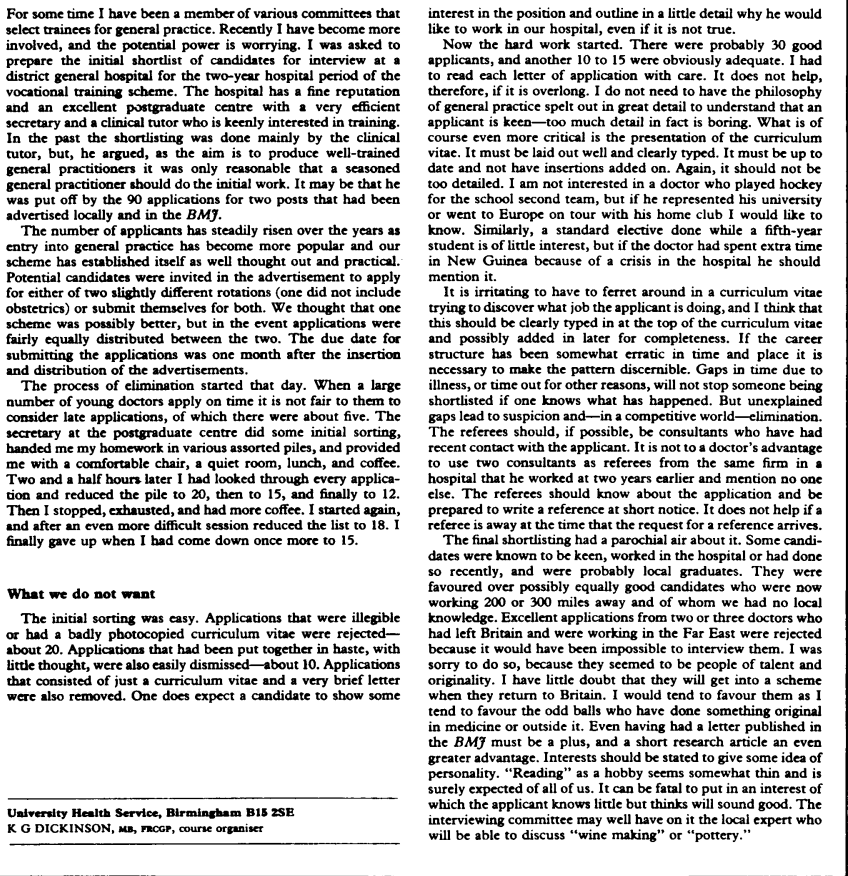

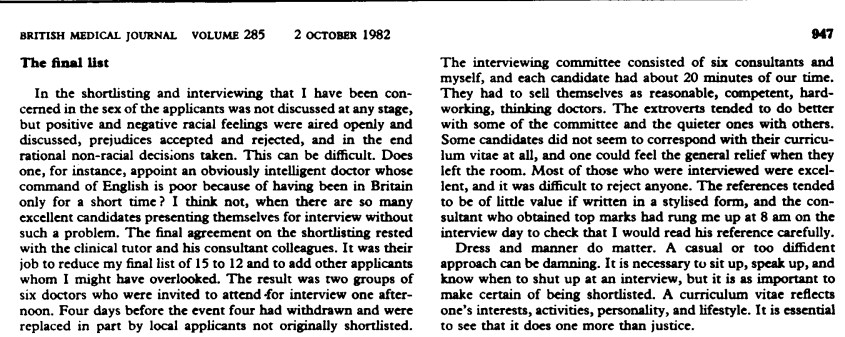

\section{Overcoming Isolation}

\section{Keeping up to date in Gateshead}

COLIN M LEON, J R YOUNG

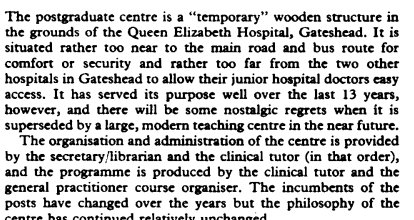
Our philosophy

We sec our postgraduate cencre as the most important locus
for the continuing medical education of the general practitioners compete with or tor teplace the organised postgraduatete training
leading to higher examinations that is organised by the academic leading to higher examinations that is organised by the academic
departments of the university The emphasis is on inter-
disciplinary discussion nearer to the "place of work" as a continuing processs in all specialties, including coommunity and
family practice. The Queen Elizabech Hospital, being only five

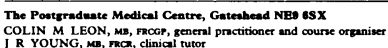

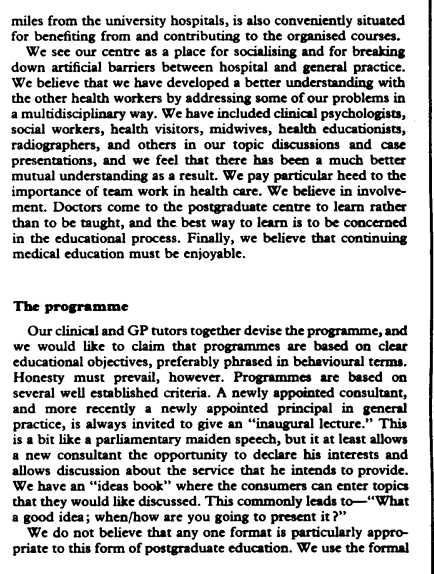

948

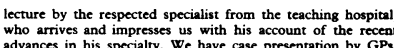

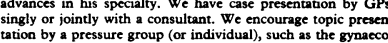

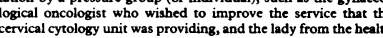

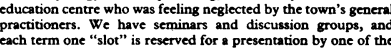

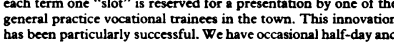

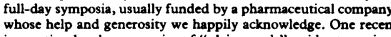

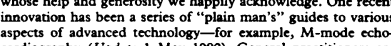

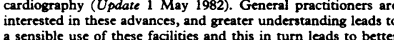

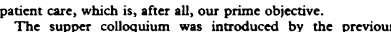

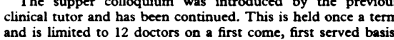

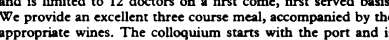

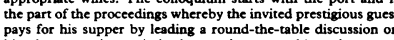

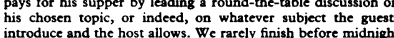

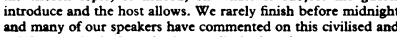

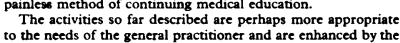
attendance of hospital doctors and others. General practictioner

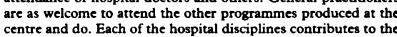

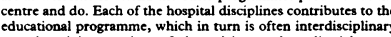

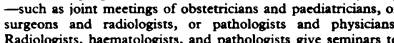

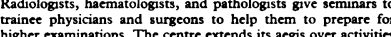

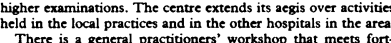

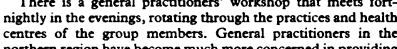

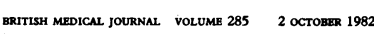

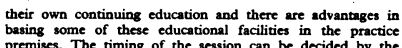

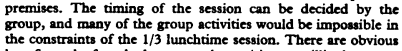

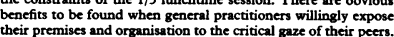

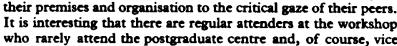

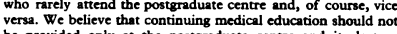

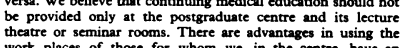

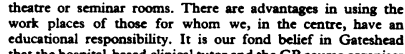

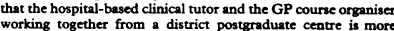

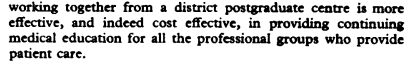
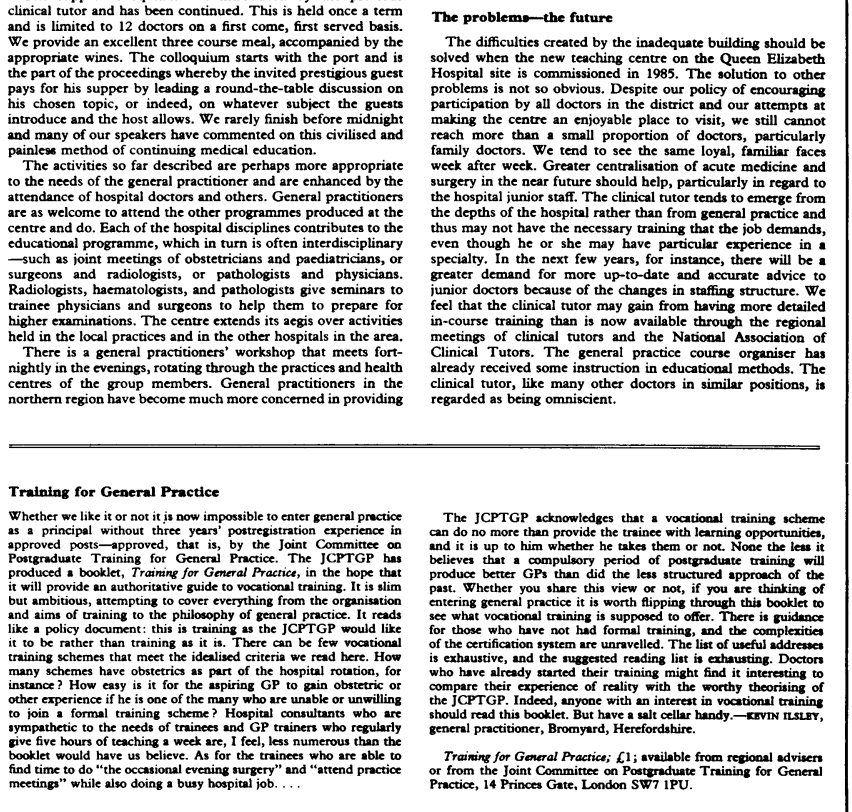